\title{
EDITORIAL
}

\section{New horizon of cancer vaccine therapy using dendritic cells made from pluripotent pluripotent stem cells}

\author{
Fukumi Furukawa ${ }^{1,2}$ \\ ${ }^{1}$ Takatsuki Red Cross Hospital, Takatsuki City, Osaka, Japan \\ ${ }^{2}$ Wakayama Medical University, Wakayama City, Wakayama, Japan
}

CORRESPONDING AUTHOR

Fukumi Furukawa, Takatsuki Red Cross Hospital, Abuno 1-chome, Takatsukishi, Osaka 569-1096, Japan; ffurukawa@takatsuki.jrc.or.jp, dajs@ wakayama-med.ac.jp

CITATION

Furukawa F. New horizon of cancer vaccine therapy using dendritic cells made from pluripotent pluripotent stem cells. Trends Immunother 2018; 2(1): 625. doi: 10.24294/ti.v2.i1.625.

Prof. Yamaue and his team, Wakayama Medical University Japan succeeded in killing the cancer cells by using dendritic cells of immune cells made from induced pluripotent stem cells very recently (Figure 1) [1].

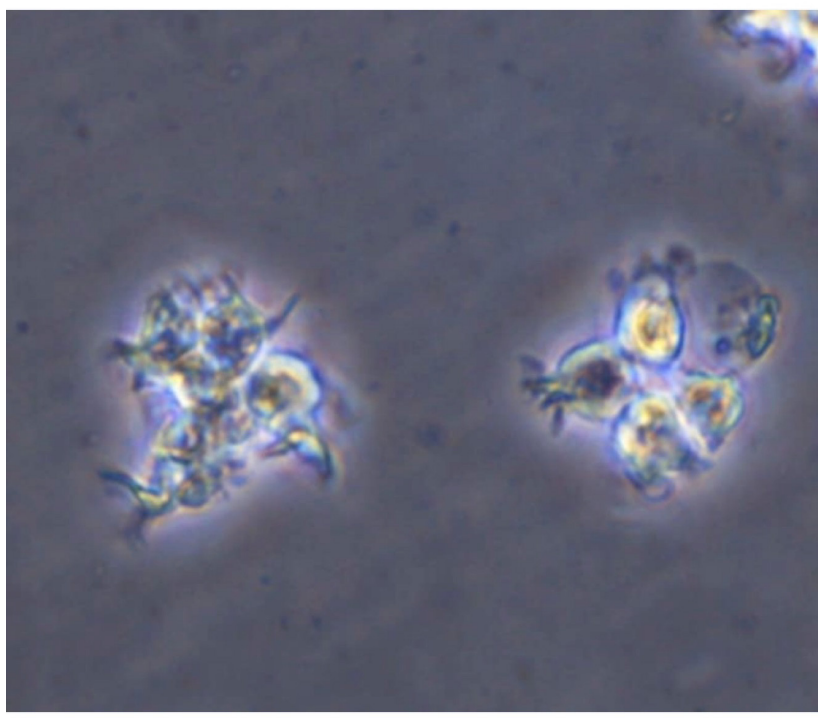

Figure 1. Dendritic cells of immune cells made from pluripotent pluripotent stem cells (courtesy by Wakayama Medical University)

One year ago, they mentioned in the review article in the first issue of Trends in Immunotherapy that immunotherapy for cancer has become an attractive therapeutic modality despite of the past numerous unequivocal clinical failures. Among several immunotherapy approaches, peptide vaccines are promising but the clinical benefits of cancer peptides vaccine have been disappointing in most studies because of several unresolved issues ${ }^{[2]}$.

In this strategy, dendritic cells (DCs) that are derived from bone marrow in vivo play for a key role in cancer vaccination as potent antigen-presenting cells within the immune system. A successful cancer vaccine needs to mount a potent antitumor immune response able to overcome the immunosuppressive tumor milieu. DCs-based approaches are a safe and promising strategy for improving the therapeutic efficacy in hematological malignancies ${ }^{[3]}$. Also DCs vaccine pulsed with peptides have been focused in order to induce powerful cytotoxic $\mathrm{T}$ lymphocytes (CTLs) in a certain type of cancer ${ }^{[2]}$.

Kitadani et al. found human iPSDCs (dendritic cells generated from induced pluripotent stem cells) expressing carcinoembryonic antigens (CEA) could induce CEA-specific cytotoxic $T$ cells against cancer cell lines endogenously expressing CEA in an in vitro model using healthy volunteers ${ }^{[1]}$. The cytotoxic $T$ cells induced by human iPSDCs transduced with full-length CEA cDNA could have strong cytotoxic activity against CEA-positive target cells in human healthy donors. Their strategy, using iPSDCs, may overcome the issues how to obtain sufficient numbers and the good condition of the vaccine components. Vaccine therapy using genetically modified iPSDCs expressing CEA is a promising clinical application for the treatment of gastrointestinal cancer ${ }^{[1]}$, in which microbiota may lead to excellent possibilities of discovering novel strategies for more effective cancer treatments ${ }^{[4]}$.

These reports strongly suggest the possibility of dendritic cells generated from induced pluripotent stem cells for immunotherapy to human cancer. 


\section{Acknowledgment}

This work was supported by a grant from the Japan Society for Promotion of Science.

\section{Conflicts of interest}

No conflict of interest was reported by the author.

\section{References}

1. Kitadani J, Ojima T, Iwamoto H, et al. Cancer vaccine therapy using carcinoembryonic antigen- expressing dendritic cells generated from induced pluripotent stem cells. Sci Rep 2018; 8(1): 4569. doi: 10.1038/s41598-018-23120-z.

2. Katsuda M, Yamaue H. Cancer vaccine therapy based on peptides. Trends Immunother 2017; 1 (1): 10-18. doi: 10.24294/ti.v1.i1.41.

3. Galati D, Zanotta S. Hematologic neoplasms: dendritic cells vaccines in motion. Clin Immunol 2017; 183: 181-190. doi: 10.1016/ j.clim.2017.08.016.

4. Tsunoda T, Shimada K, Uchida N, et al. Dynamic relationships among tumor, immune response, and microbiota. Trends Immunother 2017; 1(2): 58-66. doi: 10.24294/ti.v1.i2.79. 